\title{
ENTRE VINHOS VERDES E MADUROS: ESTUDO DE CASOS
}

\author{
Gonçalo Maia Marques \\ Instituto Politécnico de Viana do Castelo (Portugal) \\ Investigador do CEDTUR - Centro de Estudos de Desenvolvimento Turístico"
}

\begin{abstract}
Resumo: No presente trabalho, procuramos questionar e perspectivar na longa temporalidade histórica o uso das classificações de "vinho verde" e "vinho maduro" no quadro de uma nomenclatura que se foi adaptando aos usos e costumes da vinificação. Salientamos o contributo dado pelos monges beneditinos nesta clarificação e, mesmo, casos documentáveis na nobreza terratenente minhota.
\end{abstract}

Palabras-Chave: Vinho Verde, Vinho Maduro, Regiões Demarcadas, Territorialidade dos Vinhedos

Abstract: In this paper, we question the long perspective and the use of historical temporality ratings "green wine" and "mature wine" under a nomenclature that has adapted to the habits and customs of winemaking. We highlight the contribution made by Benedictine monks in this clarification, and even in cases documentary landowning nobility Minho.

Keywords: Vinho Verde, Vinho Maduro, Marks of Origin, Territoriality of the Vineyards

Resumen: En este artículo pretendemos cuestionar y presentar desde una perspectiva de larga temporalidad histórica el uso de las clasificaciones de "vino verde" " "vino maduro" bajo una nomenclatura que se ha ido adaptando a los usos y costumbres de la elaboración del vino. Destacamos la contribución de los monjes benedictinos a esta clarificación, y casos documentados en la nobleza terrateniente del Miño.

Palabras clave: Vino Verde, Vino Maduro, marcas de origen, territorialidad de los viñedos

Nos nossos dias, a afirmação das regiões demarcadas e das denominações de origem controladas ${ }^{1}$, no quadro de um mercado consumidor cada vez mais informado e global, pela sua amplitude e diversidade, induz no público consumidor e em muitos dos entusiastas da viticultura uma imagem territorial e topográfica dos vinhedos, associados às respectivas regiões matriciais, numa relação directa de causa-efeito. Parece quase impossível conceber que, no Entre Douro e Minho, se tenham produzido vinhos de outra estirpe que não seja o vinho verde, do mesmo modo que resulta inacreditável ler relatos

1 Surgem, em Portugal, como consequência da adesão à CEE (Comunidade Económica Europeia). 
que colocam na região do Douro outros vinhos para além do vinho do Porto e do afamado vinho maduro duriense.

Em tempos como os que vivemos, com as fronteiras que se vão impondo, os grémios e corporações que se vão formando em torno do importante e estratégico produto que é o vinho, importa analisar, na longa duração e na serena leitura que esta metodologia proporciona, que vinho verde e que vinho maduro temos, mas acima de tudo tivemos, tendo presente a crescente especialização de castas e, mesmo, as reconversões que a vinha tem sofrido e a implantação de outras qualidades internacionais nas nossas terras.

Outra questão determinante é a própria definição de vinho verde e vinho maduro onde acaba um e começa o outro?

Por vinho verde costuma entender-se, "vox populi" um vinho de baixo teor alcoólico (normalmente inferior a $12^{\circ}$ ) que se produz na região demarcada (correspondente, no essencial, à tradicional província de Entre Douro e Minho) e cujo consumo costumava ser associado aos grupos sociais de base, como os jornaleiros, camponeses, lavradores e outros estratos ligados à vida agrícola. Já o vinho maduro, como o próprio nome indica, deverá ser um vinho plenamente "amadurecido" na sua vinificação, com um grau alcoólico mais substantivo (acima dos $12^{\circ}$ e podendo chegar aos $16 / 17^{\circ}$ ) e que, na realidade vinícola portuguesa encontra dois "terroirs" de eleição para o seu desenvolvimento: as regiões demarcadas do Douro e do Alentejo.

Diga-se que estas "imagens" que associam o vinho verde à "uva mal sazonada" ou a um "vinho incompleto no seu processo de fermentação", que encontramos em autores como Duarte Nunes de Leão, Sá de Miranda, Lima Bezerra e Ferreira Lapa são hoje muito contestadas pela moderna investigação enológica. A Revista "Wine", do grupo Essência do Vinho, é mesmo contundente: "tal distinção, entre vinho maduro e vinho verde, pura e simplesmente não existe! Não só não existe, como é de uma injustiça atroz para com os vinhos da região do Vinho Verde, ao sugerir de forma implícita que o Vinho Verde é elaborado com uvas verdes, com uvas que não atingiram a plena maturação"2. Quer isto dizer que "vinho verde" designa, simultaneamente, uma região demarcada e uma denominação de origem controlada, mas não uma forma aparentemente alternativa de vinificação. $\mathrm{O}$ artigo esclarece, ainda, a origem da designação verde: "o nome foi adoptado por retratar de forma fiel a paisagem do Minho, a região mais verde de Portugal, a de maior índice pluviométrico, a mais fresca e viçosa do Portugal continental"' . O debate está aberto e, se analisarmos as mais recentes estatísticas dos organismos especializados, com a crescente e consistente exportação para mercados como os Estados Unidos e alguns Estados Europeus, o consumidor que aprecia o vinho verde não parece estar muito interessado com alguns "preconceitos" que a longa temporalidade foi somando às "imagens do vinho" concentrando-se muito mais facilmente no seu paladar, no seu odor e na qualidade do produto final.

2 Apreciar melhor - dicas de enofilia: vinho verde ou maduro? A distinção que não existe. In "Wine - A Essência do Vinho", consultado em 19 de Fevereiro de 2012 [disponível em http://www.essenciadovinho.com/ bluewine/php/apreciar.php?familia=2\&id=50].

3 Idem ibidem 
Com efeito, a nossa experiência de investigação em sede de doutoramento mostranos que esta realidade territorializada das regiões vinícolas é fruto, na melhor das hipóteses, de uma concepção contemporânea de organização das regiões vitivinícolas e que, na verdade, se encontram experiências de implantação de castas de origens muito diversas um pouco por todo o território nacional. Procuraremos aportar experiências desenvolvidas tanto na região demarcada do Douro como na zona de demarcação do vinho verde.

\section{AS DEMARCAÇÕES E A IDEIA DE UM "VINHO DE MARCA"}

A demarcação da região vitivinícola do Douro, em 1758, em pleno consulado pombalino, foi um dos primeiros grandes marcos de territorialização e especialização da produção vinícola no quadro do ocidente europeu. Como se sabe, o valido de D. José I procurava, com a regulamentação de uma região demarcada, dar mais poderes de regulação, tanto no plano da produção como no da comercialização que permitisse uma efectiva melhoria do valor acrescentado do produto no mercado interno e externo (CARDOSO, 2004).

Até chegarmos ao movimento global das grandes demarcações, produzia-se vinho com as mesmas características que hoje reconhecemos ao vinho verde (acidez, grau alcoólico) na região da Lourinhã (século XVI) e, mesmo, no Alentejo ${ }^{4}$. Os vinhos finos de Monção, hoje conhecidos por Alvarinhos, eram designados, na época moderna, de " $m a$ duros de Monção". Para além disso, a região vinícola da Bairrada apresentava evidentes similitudes com os vinhos minhotos, pelo que não nos deve surpreender que, dentro da actual região demarcada dos vinhos verdes, existam algumas freguesias dos concelhos de Oliveira de Azeméis e Vale de Cambra, plenamente a sul do Douro. Segundo as Memórias Paroquiais de 1758, as freguesias que compõem a região vinícola do Dão apresentam produção de vinho "embarrado" ou "feito de uvas de árvores" à semelhança do Entre Douro e Minho.

Os estudos actualmente desenvolvidos no domínio da história da viticultura, do comércio vinícola e da gestão, mostram que as regiões demarcadas estão directamente associadas a tentativas avant la lettre de qualificação e regulamentação estreita das áreas de vinhedos, associadas a um maior controlo, a montante e a juzante da produção e do comércio do precioso líquido. Segundo Gaspar Martins Pereira "a questão das marcas comerciais dos vinhos não pode dissociar-se da questão das denominações de origem, entendidas estas como «marcas regionais» ou «colectivas», que visam distinguir no mercado as «qualidades típicas» dos respectivos vinhos" (PEREIRA, 2009). Quer isto dizer que foi a demarcação, em primeiro lugar e a construção de uma denominação de origem, num segundo momento que possibilitaram a consolidação de marcas comerciais que se identificam ora como "maduras", ora como "verdes" por associação a um terroir: Entre Douro e Minho ou Douro.

\footnotetext{
4 Informações do Professor Doutor Virgílio Loureiro, a quem muito agradecemos.
} 


\section{FRONTEIRAS TÉNUES ENTRE O QUE É VERDE E O QUE É MADURO}

Os primeiros casos que aqui desenvolveremos resultam da análise da documentação da Ordem Beneditina que tivemos ocasião de compulsar, para o nosso estudo doutoral, no Arquivo Distrital de Braga (ADB).

Em 1782-84, o Mosteiro de Tibães, cabeça da Ordem Beneditina no Reino, regista no seu caderno de Estados - relatório trienal da actividade do Mosteiro que "junto ao muro da calçada que vai para $S$. Gens se principiou hua vinha de vides do Douro" (Estados de Tibães, 1782-84). O Monte de S. Gens (hoje designado Monte de S. Filipe) localiza-se bem perto da Abadia Beneditina e, como se pode verificar, foi palco de uma experiência de tentativa de implantação de castas durienses em pleno "terroir" dos verdes numa época em que já existia região demarcada.

Fotografia 1 - Vinhas velhas nas cercanias do Mosteiro de Tibães $\left(2010^{5}\right)$

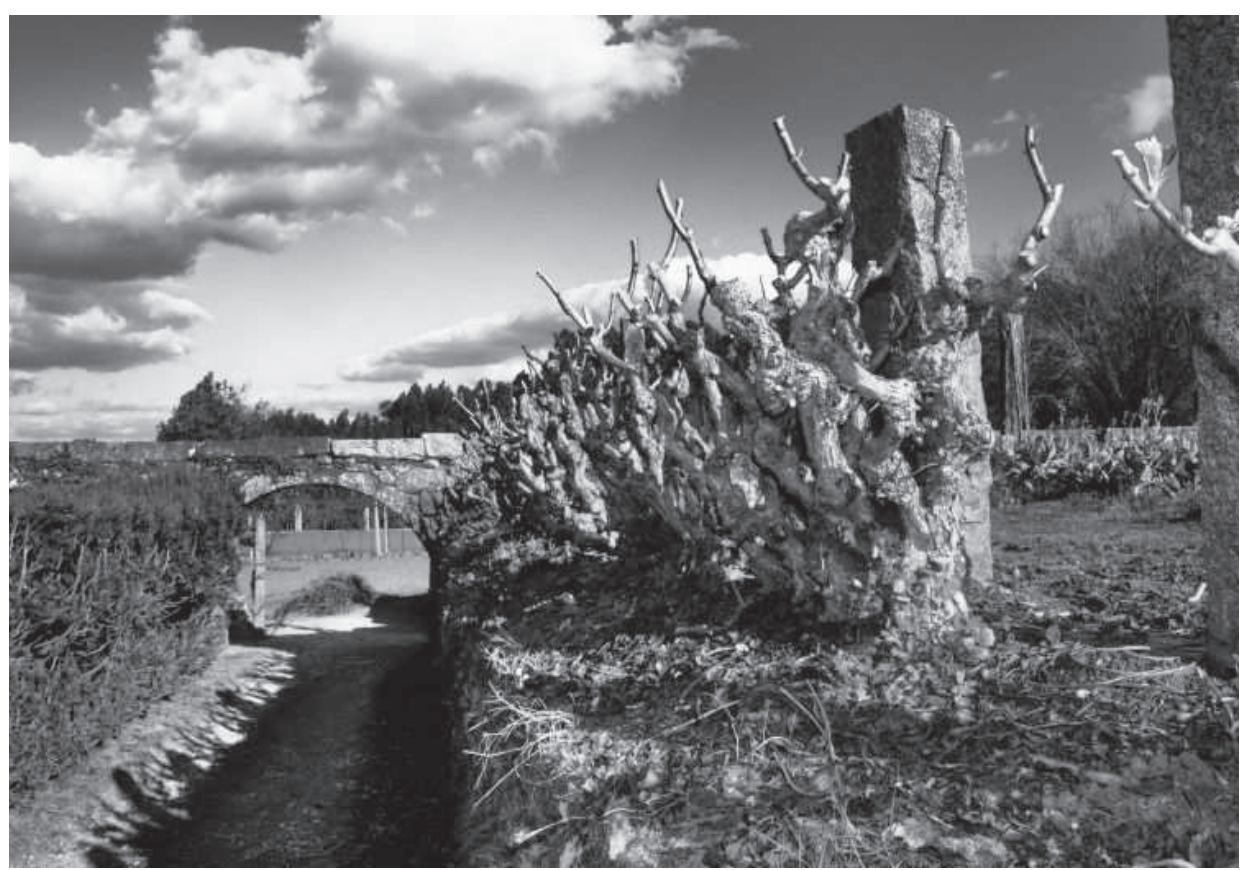

Conhecendo-se a capacidade de gestão dos religiosos o que justificaria tal intento? Como se poderia tentar que as vides durienses germinassem em pleno solo bracarense? Não nos restam grandes dúvidas que, dado o preço de mercado mais elevado dos maduros, os religiosos bem poderiam pensar na eliminação dos custos elevados do transporte desde a Região do Douro até às terras bracarenses. Note-se que o vinho maduro era

5 Autor da Fotografia: António Carlos Silva. 
aquele que, de forma mais pronunciada, era consumido na mesa monástica, pelo que a comunidade religiosa tinha deste produto maior necessidade.

Não se pense que o caso que relatamos acima se trata de uma circunstância isolada... Em 1818-20, o Mosteiro de Pombeiro regista no seu caderno de Estados que "cultivou-se um grande pedaço de terra junto da Eira e nele se plantou hua vinha de vides do Douro" (Estados de Pombeiro, 1818-20). Note-se que a eira, espaço nobre e relevante no quadro da gestão agronómica de uma casa agrícola, é escolhida para albergar vides oriundas do Douro, nos mesmos moldes e nas mesmas razões mencionadas anteriormente.

Fotografia 2 - Vinhas do Mosteiro de Pombeiro na actualidade

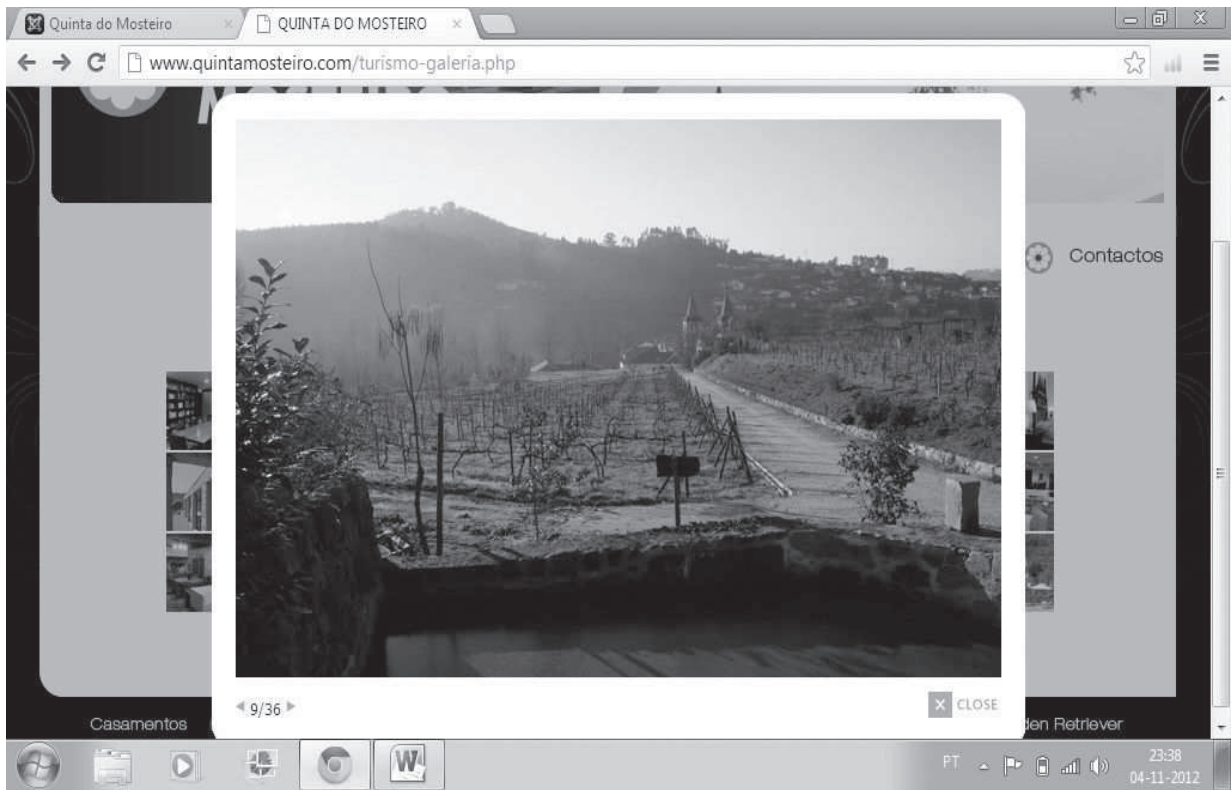

Os mosteiros beneditinos do Entre Douro e Minho procuram, deste modo, robustecer-se e preparar-se para os dias futuros. Ao produzirem, numa mesma área agrícola, vinhos de diversas estirpes e proveniências, estão a garantir, por um lado a satisfação das necessidades próprias e, por outro lado, a evolução e transmutação dos bacelos em novas qualidades, constituindo-se, assim, como verdadeiros laboratórios da vinha e do vinho no Norte de Portugal.

Igual cuidado foi colocado por estas instituições na implantação de castas de vinho verde na região demarcada do Douro. Nos "Estados" do Mosteiro de Travanca relativos ao triénio de 1731-33 encontramos um caderno específico relativo à Quinta de Medrões, localizada em Santa Marta de Penaguião. Sabe-se pelos registos que deveria ser propriedade de expressão significativa já que tinha "grande vinha, que tem de comprido 260 varas e de largo 154 que dara esta vinha de 30 athe 40 pipas do milhor vinho de feitoria, por rezão do citio e terra em que esta fabricada esta vinha". Aliás, o registo frisa que 
"esta vinha he huma das maiores de Sima do Douro e sempre do vinho della foi para a Feitoria" (Estados de Travanca, 1731-33).

Fotografia 3 - Vista geral da freguesia de Medrões, Santa Marta de Penaguião

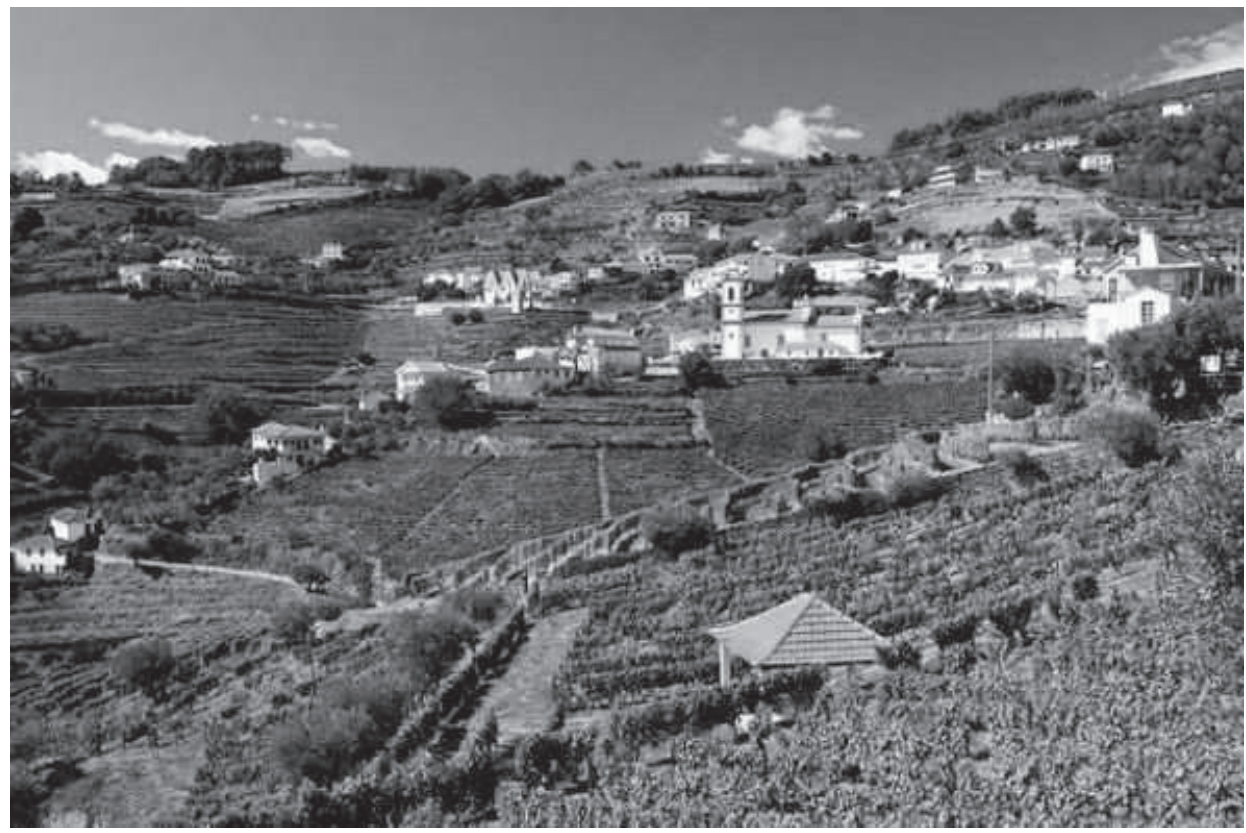

Por outro lado, dá registo de uma tentativa de integração de vides de Entre Douro e Minho em terras durienses notando-se que "fez-se nos ultimos campos, que ficão por baixo da vinha nova no Ribeiro, duas asudes ambas fortelisimas servindo estas de amparo aos campos e a mesma vinha e neste ultimo campo se mudou o ribeiro do curro antigo para outra parte para os campos ficaram com mais sementeira e pello ribeiro asima se plantarão grande numero de vaselos para vinho verde" (Estados de Travanca, 1731-33).

O "grande número" deixa-nos a impressão de que não se trataria de uma experiência circunscrita e isolada no tempo, mas que se poderia bem tratar de uma atitude ponderada, concertada e reflectida pela instituição monástica. Situando-se o Mosteiro de Travanca no concelho de Amarante, é bem possível que as castas tenham sido transplantadas da própria quinta do Mosteiro para esta vasta propriedade em Medrões. 
Fotografia 4 - Campo de vinha tradicional junto ao Mosteiro de Travanca

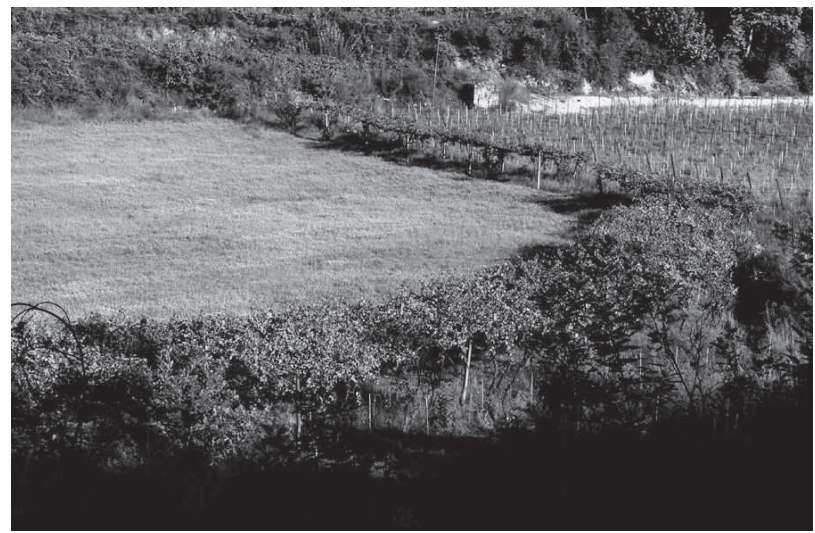

Os dados que apresentamos revelam bem como os monges bentos de Entre Douro e Minho não tinham ainda uma visão territorializada - determinista, se quisermos - dos vinhedos na sua área de "denominação de origem" (as aspas justificam-se pelo anacronismo da expressão nesta época que aqui apresenta, apenas, um sentido ilustrativo e metafórico). Desta forma, plantavam-se vinhas "verdes" na zona dos maduros e vides "maduras" na zona mais vocacionada para os "verdes" - diríamos nós, na actual concepção das demarcações.

\section{AS MISTURAS ENTRE VERDES E MADUROS}

Muitos documentos mostram que haveria, entre os religiosos, uma prática de misturar-se vinho com água, ou mesmo proceder-se à mistura de vinho de diferentes qualidades. A grande preocupação das Constituições da Ordem Beneditina é, exactamente, controlar estas (e outras) práticas desviantes que por vezes se manifestavam.

Documento 1 - São Bento entrega a Regra dos Monges ao seu colaborador Mauro

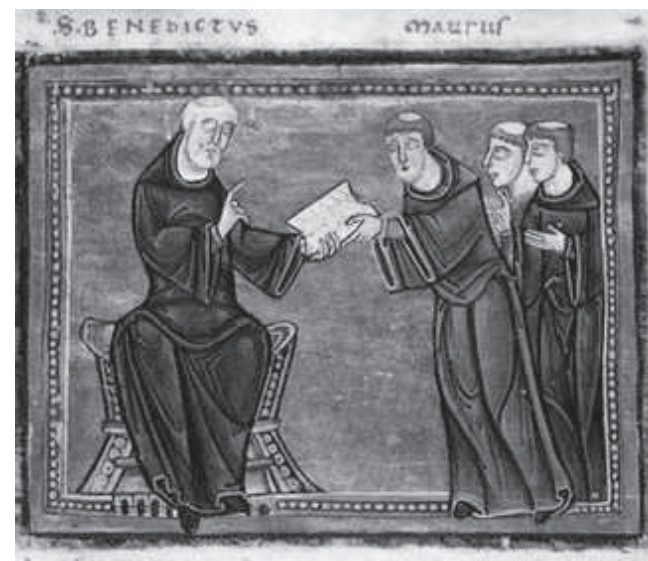


A Regra de São Bento, documento fundamental da História do Ocidente Europeu, na sua tradução portuguesa, resignava-se perante a descoberta do vinho pelos monges: "ainda que lemos que o vinho de todo não he para os monges. Mas por que nestes tempos isto se lhes não pode persuadir, ao menos nisto consintamos, que não bebamos até nos fartar, senão temperadamente: porque o vinho ainda aos sábios faz sair fora de si" (Regra de São Bento, 1586). Apesar desta realidade - e paradoxalmente - os Mosteiros Beneditinos vão tornar-se nos grandes dinamizadores e promotores da viticultura na região de Entre Douro e Minho.

No Arquivo do Solar Condes de Resende encontramos curiosas referências que importa analisar. Numa missiva datada de 8 de Abril de 1843, o $1^{\circ}$ Visconde de Beire, Manuel Pamplona Carneiro Rangel Veloso Barreto de Miranda e Figueiroa (1774-1849), avô de Emília Castro Pamplona, esposa de Eça de Queiroz, dirige-se a José Pinto da Motta, seu homem de confiança em Santa Cruz do Douro (freguesia de Baião onde se localiza a famosa Quinta de Tormes, pertença da família dos Condes de Resende) nos seguintes termos: "tenho dado a provar o vinho da Castanheira / a varios inteligentes, e todos me dizem, que he / tão bom, que he arriscado, que os provadores da / Alfandega exijão direitos de maduro; e p.r tan- / to não mande o vinho sem lhe misturar / sete ou oito almudes de vinho verde legiti- / mo, que seja são, porem do ordinario d'esse paiz [?]; e somente quero que mande huma pipa sem mistura alguma para meu gasto" (Arquivo Condes de Resende). Pensamos que se tratasse de vinho proveniente do concelho de Baião, zona célebre pelos seus vinhos de transição - entre os "verdes" e os "maduros" mais exactamente o lugar da Castanheira, da freguesia de Santa Leocádia, actual núcleo urbano da vila de Baião. Com efeito, a qualidade do vinho em apreço, tanto do ponto de vista degustativo, quanto pela graduação alcoólica que atingia, espanta o círculo próximo do Visconde de Beire, chegando os funcionários alfandegários a tomá-lo por "maduro". Bem poderíamos colocar, uma vez mais, a sacramental pergunta: onde acabam os verdes e começam os maduros?

O próprio Visconde pede que sejam adicionados "sete ou oito almudes" (o equivalente a 117,6 ou 134,4 litros, se tomarmos a medida de 16,8 litros para o almude do reinado de D. Manuel $\mathrm{I}^{6}$ ) característicos do "país" dos verdes, ou seja, o Entre Douro e Minho, com o intuito de o tornar mais "verde" e menos "maduro" e assim, certamente, escapar a uma taxação de "maduro". E o Visconde insiste: "e de modo nenhum me mande o vinho / sem a mistura que digo; porem haja cuidado, que seja bom e são o vinho, que se comprar; que não estrua [sic] o da Castanheira. Pelo que respei- / ta aos foros pedidos

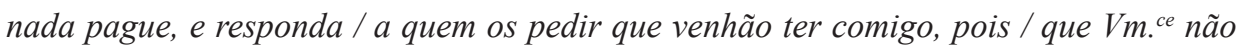
está authorizado para isso" (Arquivo Conde de Resende).

6 Conforme o Regimento de Pesos e Medidas para a Cidade de Lisboa, do Reinado de D. Manuel I ao qual tivemos acesso. 


\section{ALGUMAS LEITURAS EM JEITO DE CONCLUSÃO}

Perante o que fica exposto neste trabalho, ressalta a dúvida: onde começam afinal os verdes e terminam os maduros? Para além de uma tradição produtiva, das idiossincrasias das regiões demarcadas e dos mecanismos que resultam nas respectivas denominações de origem, importa perceber que as barreiras psicológicas e alguns mecanismos que, de forma artificiosa, tendem rotular este vinho como verde e aquele como maduro podem esbarrar no espartilho da sua própria rotulagem.

Se dúvidas houvesse, permitíamo-nos terminar com um exemplo elucidativo: quem diria que um vinho que apresenta duas castas tradicionais da região dos vinhos verdes - vinhão e borraçal - cuja área de vinhedos se localiza em Arcos de Valdevez e cujo "terroir" se identifica com as características geomorfológicas do Entre Douro e Minho poderia resultar numa "pomada" que obtém uma variação alcoólica, dependendo da colheita, entre os 12 e os 14 graus? Falamos do vinho Aguião, cuja produção, eminentemente tradicional, o torna um vinho de eleição e que, dentro dos parâmetros aqui analisados, é bem exemplificativo de quão ténue é a barreira semântica entre vinhos maduros e verdes.

Fotografias 5 e 6 -Aguião, Colheita 2011 (à esquerda) e Torre de Aguiã (à direita)
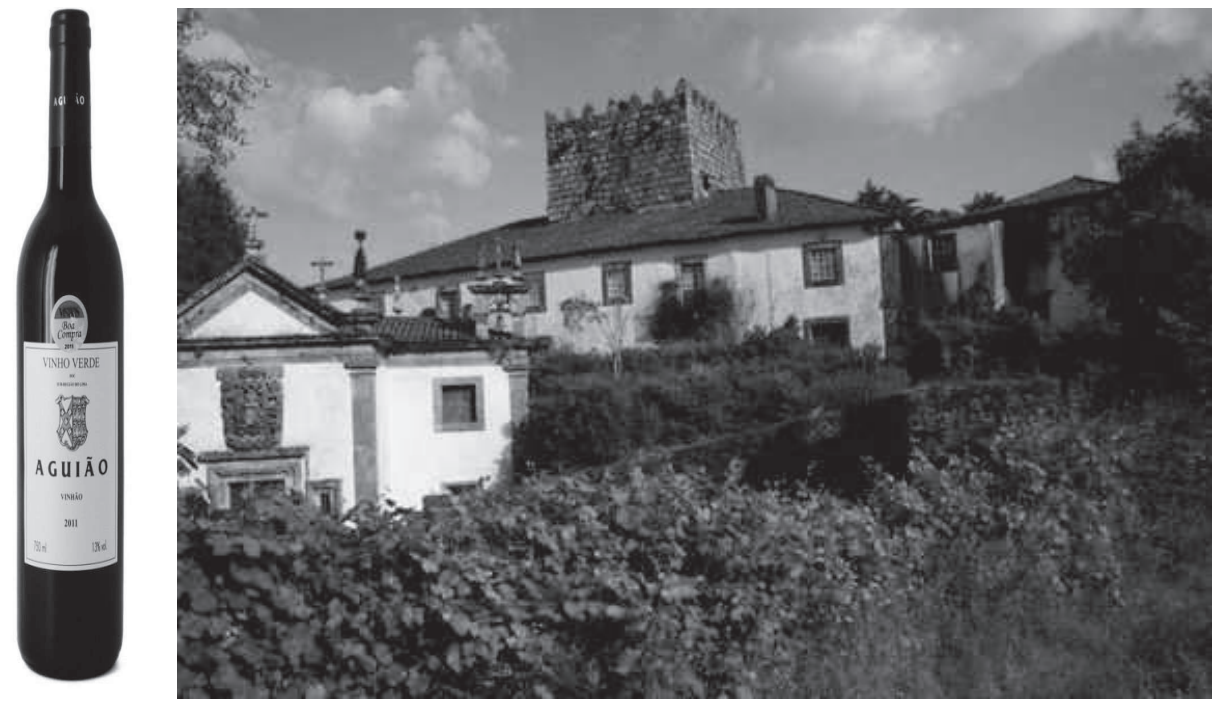

Que implicações poderá esta reflexão ter na prática turística? Uma saudável promoção da diversidade que deve sempre primar pela defesa da autenticidade dos produtos, mesmo que isso implique comunicar formas e conteúdos alternativos à imagem de uma região demarcada imutável, cuja paisagem não foi transformada pelo Homem e, acima de tudo, sem melhorias qualitativas para apresentar. Isto, sim, seria empobrecedor para o turista que nos visita e para o agente turístico que, ao invés de promover, está a incentivar o turista a não regressar ao destino e a tornar-se, desta feita, num one trip tourist. 
Oxalá que a diversidade seja a tónica de uma promoção turística que se quer cada vez mais informada quanto aos conteúdos a apresentar.

\section{FONTES CONSULTADAS}

Arquivo Distrital de Braga - Universidade do Minho:

Congregação de São Bento (CSB), Estados do Mosteiro de São Martinho de Tibães [3 pastas, 1626-1820].

Congregação de São Bento (CSB), Estados do Mosteiro de Santa Maria de Pombeiro [2 pastas, 1626-1820].

Arquivo do Solar Condes de Resende (ASCR) - Arquivo dos Condes de Resende, Pasta 7, Copiador 3, fol. 111.

Biblioteca Nacional de Portugal - Regra do Glorioso Patriarcha Sam Bento tirada de Latim em lingoajem portuguesa por industria do muito R. P. F Placido Villalobos Geral nesta Congregação de Portugal. Lisboa: Impresso por António Ribeiro à custa da Congregação de São Bento, 1586.

BEZERRA, Manuel Gomes de Lima - Estrangeiros no Lima (...). 2 Tomos. Coimbra, Imprensa da Universidade, 1785.

LEÃO, Duarte Nunes de - Descripção do Reino de Portugal. Lisboa: Impresso com licença por Jorge Rodriguez, 1610.

\section{BIBLIOGRAFIA CONSULTADA}

CARDOSO, António Barros (2004): Baco e Hermes: o Porto e o comércio interno e externo dos vinhos do Douro (1700-1756). Porto: GEHVID, 2 vols.

GUIMARÃES, Susana (2006): A Quinta da Costa em Canelas, Vila Nova de Gaia (17661816). Gaia: Associação de Amigos do Solar Condes de Resende - Confraria Queirosiana.

MARQUES, Gonçalo Nuno Ramos Maia (2011): Do vinho de Deus ao vinho dos homens: o vinho, os mosteiros e o Entre Douro e Minho. Porto: Dissertação de Doutoramento em História apresentada à Faculdade de Letras do Porto.

OLIVEIRA, Aurélio de (2010): No País dos Verdes: trabalho, tradição e diversão. Porto: APHVIN/GEHVID e Confraria do Vinho Verde.

PEREIRA, Gaspar Martins (2009): O nome do vinho: marcas e denominações dos vinhos generosos do Douro (séculos XVIII-XX). In Comunicação apresentada ao XXIX Encontro da APHES. Porto: APHES e FLUP. 